\title{
Outros Espaços de aprendizagem Da Máscara aos Saberes Sobre Ciências
}

\author{
Alessandro Cury Soares ${ }^{1}$ \\ Rochele de Quadros Loguercio²
}

\begin{abstract}
Resumo
Este trabalho tem como objetivo mostrar nosso entendimento sobre outros locais em que podemos aprender sobre Ciências, sinalizando para a potência do desfile das escolas de samba (seu universo) e as aprendizagens que podem ocorrer no seu entorno, por meio dos monumentos encontrados. Para tanto, realizamos análise destes documentos/monumentos com inspiração na análise de discurso de Michel Foucault.
\end{abstract}

Palavras-chave: Educação. Documentos. Carnaval.

OTHER LEARNING SPACES:

The Mask to Know About Science

\begin{abstract}
:
This paper is intended to show our understanding about places that we can learn about science, signaling to the power of the parade of samba schools and learning that can occur in your environment, through the monuments found. To this end, we conducted analysis of these documents/monuments with inspiration in speech analysis of Michel Foucault.
\end{abstract}

Keywords: Education. Documents. Carnival.

${ }_{1}$ Universidade Federal do Rio Grande do Sul - Programa de Pós-Graduação em Educação em Ciências: Química da Vida e Saúde. alessandrors80@gmail.com

2 Universidade Federal do Rio Grande do Sul - Programa de Pós-Graduação em Educação em Ciências: Química da Vida e Saúde. rochelel@gmail.com 
As questões relativas ao ensino de Ciências e como este pode ser concebido transitam entre as diferentes formas - espaços - em que o ensino pode ocorrer. Tradicionalmente, conhecemos a escola (em suas diferentes apresentações - seriada, por ciclos, tradicionais, construtivistas e outras) como sendo o local para que se constituam os saberes formais.

No ensino de Ciências isso não é diferente, pois a maioria dos pesquisadores (VIEIRA; BIANCONI; DIAS, 2005; MARANDINO, 2005; PINTO; FIGUEIREDO, 2010) continua apontando para espaços informais de aprendizagem compreendidos como a família, os vizinhos, o cotidiano, o trabalho; espaços formais de aprendizagem a escola, a universidade e espaços não formais de aprendizagem os museus, os centros de ciência e de cultura.

Nesse sentido, podemos pensar que aprender Ciências é sobretudo uma prática social, ela está diretamente ligada ao fato de vivermos em sociedade e sermos interpelados por diversos discursos, inclusive o das Ciências, constituindo a cultura (que tem em sua base a ciência) e criando condições de gerarmos uma aprendizagem sobre Ciências em diferentes espaços, inclusive - em nossa perspectiva - no desfile de uma escola de samba.

Os espaços não formais (ou seriam informais?) de aprendizagem podem lançar mão de algumas linguagens (recursos didáticos) e sensações que de fato não sejam possíveis de ser acessadas na escola, criando possibilidades de aprendizagem em outros lugares. No caso de nosso estudo, especificamente, pensamos nas linguagens ${ }^{3}$ acionadas pelas escolas de samba ao tratar de um tema, as emoções ali acionadas e a potencialidade destes argumentos para constituirmos um saber sobre vários assuntos, inclusive sobre a ciência - de forma interdisciplinar e não fragmentada.

Para efeitos de nossa compreensão nos valeremos da expressão cunhada por Falk (2002, p. 62) Free-Choise Learning (aprendizagem por livre escolha). ${ }^{4}$ Escreve ele:

\footnotetext{
${ }^{3}$ Para mais informações, acessar a tese intitulada: Entre confetes e serpentinas é a ciência pedindo passagem.

4 Termo já consagrado no Brasil por outros autores como Ovigli et al. (2007) e Arruda et al. (2013).
} 
Learning is something we do all the time, throughout our lives. Learning happens in school and at home, in classrooms, in workplaces, in museums, while watching television, while playing sports and while talking with friends (Falk, 2001). We learn both through formal instruction and on our own. Some of what we learn, we learn because we have to learn it. If we want to drive a car, we need to learn the rules of the road and pass a driving test. If we want to practice medicine, we need to learn about the human body and how it functions and pass a boardcertified examination. However, most of what we learn in our lives we learn not because we have to, but because we want to, because events in our life intrinsically motivate us to find out more (McCombs and Whisler, 1989; McCombs, 1991). Under these conditions, we learn not only what we want, but also where we want, when we want, and with whom we want. This is free-choice learning - lifelong learning that is intrinsically motivated and largely under the choice and control of the learner (FALK; DIERKING, 2000).

Em outras palavras, necessitamos aprender, seja onde for: em casa, nas escolas, em um desfile... Qualquer local é possível e passível de constituir um conhecimento sobre algo. Nesse sentido afirmamos a constituição de saberes sobre a ciência nos desfiles das escolas de samba cariocas.

Outra questão é relativa à constituição deste saber: não acreditamos ser possível quantificar ou qualificar a aprendizagem nesses espaços nos quais ocorre a aprendizagem por livre escolha, tendo em vista que primeiramente este não é o objetivo nem deste estudo, tampouco dos espaços não formais/informais. $\mathrm{O}$ que podemos é indicar por meio de nossas análises dos ditos ${ }^{5}$ é que existe um saber constituído nesse local. Quanto à Ciência, compartilhamos das palavras do então ministro da Ciência e Tecnologia - Eduardo Campos - que reconhece o desfile como a possibilidade de ali se formar um conhecimento

Observa ele:

[...] Num momento de festa, um momento de alegria, mostrar ao povo brasileiro o conhecimento acumulado pelo homem, pela civilização e a necessidade do Brasil, levar a ciência das Universidades, dos Institutos pro cotidiano

5 Para mais informações, acessar a tese intitulada: Entre confetes e serpentinas é a ciência pedindo passagem. 
do nosso povo, sobretudo pro povo mais marginalizado, mais sofrido, que pode ter na ciência uma grande aliada pra melhorar sua qualidade de vida (YOUTUBE, 2004, 8”-33").

Outros autores como Ovigli et al. (2007, p. 3) argumentam que:

Pesquisas recentes sugerem que uma grande parcela da aprendizagem e compreensão sobre ciência pelo público é oriunda do setor de livre aprendizagem. Este inclui museus, televisão, rádio, Internet, revistas, jornais, livros, parques e organizações comunitárias de todo tipo: juvenis, de adultos, religiosas, ambientalistas, de saúde, esportes e recreação.

Sendo assim, parece-nos importante sinalizarmos para este espaço - o desfile das escolas de samba - como sendo este mais um local em que é possível se constituir saberes sobre a ciência. Coube ao nosso trabalho tornar esse espaço visível, pois embora existente desde os idos da década de $30,{ }^{6}$ poucas ${ }^{7}$ ou raras são as pesquisas na área de ensino de ciência, ensino de Química ou de educação pura, gerando um espaço para análise, para focarmos nosso olhar e buscarmos elementos para que se compreenda primeiramente o que se aprende e talvez em outro momento o de como se aprende neste local.

\section{A Metodologia}

A ideia que nos move neste momento perpassa pelo desejo de mostrarmos alguns materiais que recolhemos/escolhemos ao longo desta pesquisa, que faz parte de um trabalho de Doutoramento, e que tornam possível observar alguns ditos da ciência no entorno do desfile - no seu processo de construção, seja an-

${ }^{6}$ Quando mencionamos este fato referimo-nos aos desfiles das escolas de samba.

7 Destacamos este como sendo um dos únicos trabalhos que encontramos na área de educação em Química: MAIA, Eline; MESSEDER, Jorge C. Carnaval e ciência: uma proposta CTSA a partir da vivência no barracão do GRES Beija-Flor de Nilópolis. III ENCONTRO NACIONAL DO ENSINO DE CIÊNCIAS DA SAÚDE E DO AMBIENTE, 3., 2012, Niterói. Anais... Niterói: Campus da Praia Vermelha/UFF, 2012. 
tes, seja durante, seja após este desfile, permitindo-nos fazer uma análise deste material, ${ }^{8}$ haja vista que o tomamos como monumentos que em nosso trabalho são entendidos como:

Em nossos dias, a história é o que transforma esses documentos em monumentos e que desdobra, onde se decifravam rastros deixados pelos homens, onde se tentava reconhecer em profundidade o que tinham sido, uma massa de elementos que devem ser isolados, agrupados, tornados pertinentes, inter-relacionados, organizados em conjuntos. Havia um tempo em que a arqueologia, como disciplina dos monumentos mudos, dos rastros inertes, dos objetos sem contexto e das coisas deixadas pelo passado, se voltava para a história e só tomava sentido pelo restabelecimento de um discurso histórico; poderíamos dizer, jogando um pouco de palavras, que a história, em nossos dias se volta para a arqueologia - para a descrição intrínseca do monumento (FOUCAULT, 2007, p. 8).

É importante salientar que não tentamos criar uma maneira de mostrarmos todos os documentos/monumentos que encontramos, elencamos apenas alguns que nos permitem contar um pouco mais de onde se pode observar ditos sobre a ciência no espaço dos desfiles ou para além destes. Esta maneira descontínua é cunhada por Foucault e se refere a um método de se olhar para a constituição da sociedade. Conforme Foucault (2007):

Assim definida - mas vê-se de imediato o quanto é difícil fixar-lhe limites precisos -, a história das idéias se dirige a todo esse insidioso pensamento, a todo esse jogo de representações que correm anonimamente entre os homens; no interstício dos grandes monumentos discursivos, faz aparecer o solo friável sobre o qual repousam. Trata-se da disciplina das linguagens flutuantes, das obras informes, dos temas não ligados. Análise das opiniões mais que do saber, dos erros mais que da verdade; não das formas do pensamento, mas dos tipos de mentalidade (p. 155).

8 Esclarecemos que estes monumentos (são eles: textos, charges, matérias veiculadas na imprensa e outros) foram nos encontrando ao longo dos quatro anos de pesquisa e que se tornam importantes por nos permitirem falar sobre ciência neste espaço. 
Ou ainda nas palavras de Fischer ${ }^{9}$ temos de fazer "falar" os monumentos e entendemos como monumentos as revistas, os documentos, as fotos, páginas de Internet e os materiais que compõem nossa pesquisa, pois isto faz parte do modo foucaultiano de contar uma pesquisa, de olhar para o campo.

Nesse sentido é um pouco disso que tentamos mostrar. Após sinalizarmos para a importância deste espaço, buscamos tornar visível a ciência que se encontra além dos muros da Sapucaí, mas que está intimamente ligada com esse ambiente. De forma alguma queremos entender que os enredos dependem destes fatos ou que estes fatos são desdobramentos dos enredos que tratam de assuntos sobre a ciência (haja vista que isso seria prematuro, distante da nossa maneira de analisar e não é nossa intenção).

Queremos apresentar um pouco mais desta ciência, mostrar seus rastros, seus documentos/monumentos, pois eles nos permitem analisar, relacionar e observar essa ciência presente nos desfiles.

9 Em fala realizada na banca de defesa da tese de Doutorado em Educação em Ciências, de Bruno dos Santos Pastoriza, cujo título é Educação Química em Discurso, ou sobre um modo de olhar para a prática da Educação Química, realizada em 18 de dezembro de 2015. 


\section{Beleza: a que preço?}

Figura 1 - Charge sobre a representação da fantasia

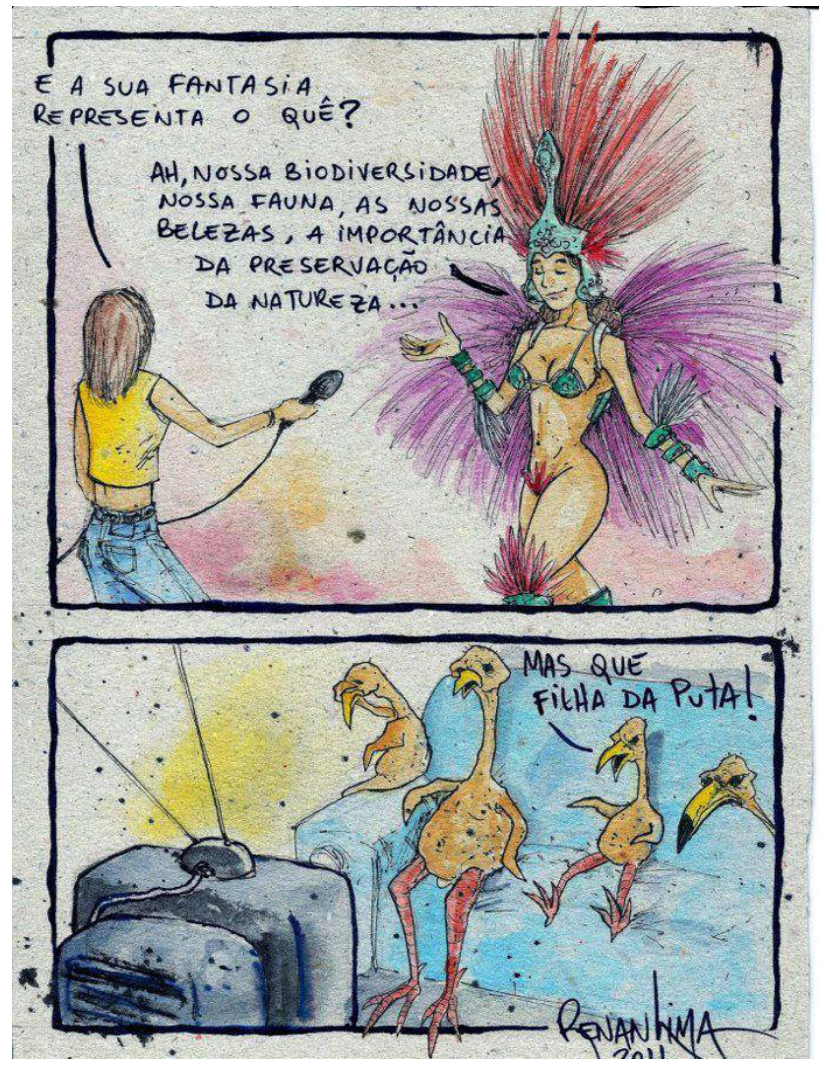

Fonte: KINGVENDAS (2012).

Nesse sentido, pensar o discurso ambiental da escola não significa definitivamente cobrar coerência de sua organização. Há, nos discursos, uma determinada ordem, nos discursos que se colocam como os "discursos da ordem" fluem tranquilamente os sujeitos e os lugares que ocupam. Nesse sentido, a incoerência não é incoerente, é imanente. 
Embora muito já se tenha dito a respeito da proteção e preservação Figura 1 - dos animais nas próprias escolas de samba, ainda observamos o uso indiscriminado de plumas e penas naturais nas fantasias confeccionadas - vale aqui lembrar o antológico enredo da Unidos da Ponte de 1989: Vida que te quero viva.

\author{
S.O.S. à Mãe Natureza \\ Parem serras e queimadas (bis) \\ Deixa a beleza
}

Que saudade de Sete Quedas

Da passarada, o rio mar (ô, rio mar)

Do nosso boto cor-de-rosa

A tartaruga onde está?

Mico Leão, não pare de pular

Mico Leão, querem te pegar (bis) (LETRAS, 1989).

Este enredo faz uma severa crítica às questões ambientais, mas embora tenhamos constatado aprendizagem, fica a questão: Aprendemos na teoria? $\mathrm{Ou}$ nem na teoria? Haja visto que prática não se tem. Alguns pesquisadores de indumentária e figurinos poderão argumentar que o uso de "tal" material faz parte da tradição das escolas de samba e que a beleza deste material é ímpar (com o que não discordamos), apenas fazemos algumas ressalvas e a primeira delas diz respeito ao conceito de tradição - uma construção cultural como qualquer outra, podendo, portanto, ser ressignificada.

Cabe perguntarmos: Não estaria na hora de criarmos outras tradições para os desfiles? Afinal, já existe uma série de penas artificiais capazes de substituir as naturais.

Nosso segundo argumento vem no sentido de pensarmos como estes animais são produzidos. Sob quais condições? Pois a maioria deles é produzida em confinamento com uso de hormônios e de iluminação artificial para acelerar seu crescimento, conforme afirma Pedroso (2014). A questão aqui é outra: 
Embora seja um procedimento para a criação de galináceos (pavões, faisões, emas e galinhas) é este um método que se preocupa com a qualidade de vida destes animais?

Outro argumento é retirado da atual situação financeira brasileira, que não é das melhores, noticiam os jornais:

Monstros sagrados na confecção de fantasias de luxo de 13 escolas - do Grupo Especial e de Acesso — os estilistas Leonardo Leonel, o Leozinho, e Leandro Santos, o Pedrão, dormem e acordam pensando no dólar. Pedras importadas da Austrália variam de $\mathrm{R} \$ 2$ a $\mathrm{R} \$ 80$, a unidade. Plumas que custavam $\mathrm{R} \$ 900$ valem $\mathrm{R} \$ 1.600$.

O negócio é reaproveitar acessórios. 'É preciso deixar cada figurino, cada roupa, ainda mais bonito com criatividade', sustenta Leozinho. O conjunto de fantasias do $1^{\circ}$ casal de mestre-sala custou este ano R \$ 120 mil. Mas, para 2016, a estimativa é de $\mathrm{R} \$ 160$ mil, mas a maioria das escolas não querem por mais de R\$ 80 mil (CRUZ; MOURA, 2015).

Não está na hora de revermos os custos, afinal 5 milhões de reais por escola não é muito dinheiro? Temos de investir no espetáculo, é certo, mas quanto? Não está na hora de fiscalizarmos de perto onde e como são investidos estes recursos? Enfim, inquietações que não pretendemos responder, apenas queremos pensar.

Nossa última pergunta: Até quando nos valeremos da fragilidade dos animais para satisfazermos nossa vaidade? O que estamos de fato aprendendo?

\section{Os rescaldos da folia}

Afirmamos neste trabalho de pesquisa que é possível aprender sobre temas da ciência nos desfiles, entretanto podemos pensar que não se aprende só com os temas relativos às Ciências, mas também quando acionamos estes conhecimentos (da ciência) no universo do carnaval, afinal tais atitudes tornam-se notícias sendo divulgadas nas mídias. Sulaiman (2011) narra em seu trabalho que antes mesmo do processo de globalização já se aprende uma série de saberes nas mídias. 
Nesse sentido podemos pensar numa série de reportagens que surgem ao longo do ano - no pré-carnaval - e que algumas delas (ao longo da nossa pesquisa), conforme a temática, foram selecionadas para apresentarem estes exemplos de possível entendimento de temas da ciência para além do desfile.

O primeiro exemplo diz respeito à reciclagem de isopreno, conforme a reportagem (DA REDAÇÃO, 2014):

O maior evento de Carnaval do Brasil, que começa nesta quinta-feira, dia 31 de julho, no Centro de Convenções SulAmérica, no Rio de Janeiro, trará novidades e lançamentos de mais de 50 expositores que farão parte da feira. Um deles é da ProEcologic, empresa que traz solução inédita para o Carnaval: uma máquina de $1 \mathrm{~m}^{2}$, que processa e reaproveita os restos do isopor, transformando-os em molduras, rodapés e porta-retratos, entre outros produtos.

Os restos de isopor usados nas alegorias das escolas de samba são um grande problema para as agremiações: o material é difícil de descartar e polui o meio ambiente. A tecnologia foi desenvolvida em parceria com a Santa Luzia Molduras-SC.

Com ela, é possível retirar o oxigênio do isopor, que passa por redução de até $92 \%$, transformando-se numa massa e, depois, em grãos, que são a matéria-prima para os objetos. Nos aterros sanitários, o isopor leva 150 anos para se decompor.

A Carnavália-Sambacon, que acontece até o dia 2 de agosto, deve gerar pelo menos R 10 milhões em negócios a partir da interação de representantes da indústria, do comércio de acessórios de fantasias e alegorias e de equipamentos. Também participam carnavalescos, artesãos, produtores, jornalistas e representantes de órgãos públicos. 
Figura 2 - Máquina de Reciclagem de Isopor

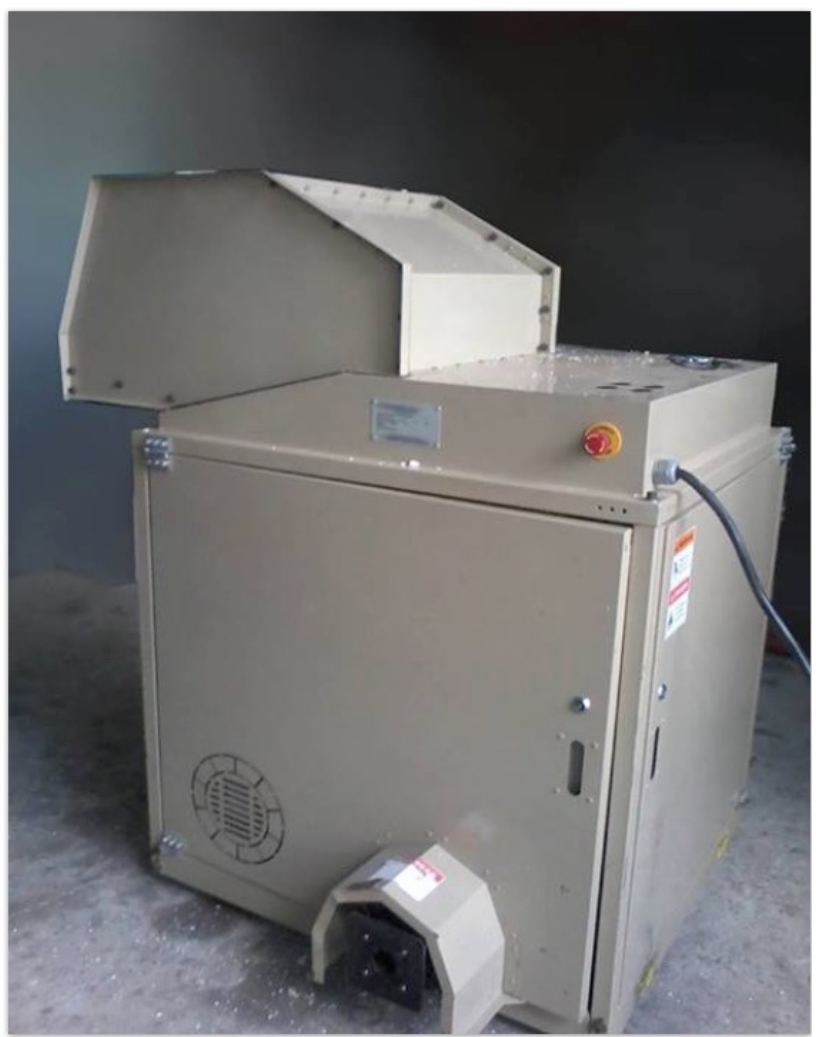

Fonte: Registro dos arquivos do autor.

O que se lê de forma alguma pode ser entendido como científico, tampouco se pode desprezar o que está dito, haja vista que é uma tentativa de dialogar com o público - com o uso de uma linguagem não técnica - , de sinalizar para a importância de reciclar o isopor utilizado para a confecção de esculturas que geram grande quantidade de resíduos.

Outro aspecto que destacamos diz respeito à crise hídrica que se instalou sobre a Região Sudeste em 2015 e que esteve presente em todas as mídias. Ela também tornou-se objeto de pensamento das escolas de samba cariocas que utilizam/utilizavam muita água para os efeitos especiais em suas alegorias. 
A crise hídrica que ameaça o Rio de Janeiro com o racionamento de água caso não chova nos próximos meses e os níveis dos reservatórios continuem baixando - está fazendo com que as escolas de samba do Grupo Especial do Rio reavaliem os projetos que previam o uso de água em suas alegorias.

A Unidos do Viradouro, por exemplo, que usaria 40 mil litros de água em seu primeiro carro, decidiu reduzir para 10 mil litros em reunião realizada nesta segunda-feira (26). A decisão foi tomada entre o carnavalesco João Vítor Araújo, o presidente Gusttavo Clarão e diretores da escola.

Já a União da Ilha do Governador, segundo o presidente Ney Filardi, se antecipou à crise. Ele contou que quando o carnavalesco Alex de Souza projetou o último carro da escola, pensou-se na utilização de 3.500 a 4.000 litros de água para representar a fonte da juventude. Mas diante das dificuldades de abastecimento que vinham assolando a região Sudeste, o projeto foi modificado em maio.

"Diante das dificuldades, decidimos dizer não ao desperdício. Não vamos mais utilizar água neste carro e nem no tripé da banheira de Cleópatra. $\mathrm{Na}$ última alegoria, optamos pela utilização de efeitos de luz e outros efeitos. Já Cleópatra vai continuar tomando o seu banho de 'leite de cabra', mas sem usar água. O que ela vai usar vai ser uma surpresinha que a escola vai deixar para revelar na avenida”, disse o presidente. [...] (MENDONÇA, 2015).

Com esse recorte mostramos a preocupação com o ambiente e sua manutenção - pelos setores responsáveis pelo projeto do desfile - articulando a responsabilidade das escolas de samba, que muitas vezes são apontadas como fonte inesgotável de gasto de recursos públicos, sem levar em conta esse tipo de proposição de seus desdobramentos que podem fomentar pequenas discussões familiares até mesmo sobre papel da ciência na solução da crise hídrica, que em última análise perderia seu status de vilã da sociedade (armas químicas, bombas atômicas, agrotóxicos, poluição) para ganhar o status de possível responsável pela solução de problemas.

Conforme Sulaiman (2011, p. 646):

Esse "trocar a ciência em miúdos", segundo Reis (1982), tem sido fundamental na compreensão da propalada crise ambiental contemporânea, muito relacionada tanto com os efeitos nocivos do desenvolvimento científico e 
tecnológico - gases de efeito estufa, lixo tóxico, insumos agrícolas - quanto com o avanço da tecnologia limpa para a sustentabilidade - biodiesel, reciclagem, agroecologia.

Dessa maneira, temos a ciência ganhando outros contornos por meio do desfile das escolas de samba ou ainda pela publicidade que invade e também constitui o desfile, podendo gerar saberes sobre as Ciências.

Em nossa busca nos deparamos no ano de 2016 com uma manchete que anuncia que uma escola de samba do Grupo Especial carioca utilizaria uma alegoria sustentável, conforme excerto extraído:

Em época de crise financeira, a Mocidade Independente de Padre Miguel, decidiu não só buscar alternativas mais baratas, como também sustentáveis. A prova é a quinta alegoria da escola, denominado "Sacra insurreição", que, com exceção da estrutura de ferro e da base de madeira, é todo confeccionado com material natural ou reciclado.

No enredo "O Brasil de La Mancha: sou Miguel, Padre Miguel. Sou Cervantes, Quixote cavaleiro, Pixote brasileiro", o carro vem representando o Nordeste, retratando o sofrimento de retirantes nordestinos por causa da seca, da fome e da miséria. O carro traz figuras que seguem numa procissão de fé e esperança.

Para dar a ideia de aridez, os carnavalescos Alexandre Louzada e Edson Pereira usaram muito bambu, bucha vegetal, galho seco, além de sobras de borracha e isopor. No carro, além de figuras famélicas e tristes com pintura que imita madeira, haverá mais 45 componentes e um destaque. [...] (MENDONÇA, 2016).

É a primeira vez que se fala em alegoria sustentável no desfile das escolas de samba cariocas. Embora esse tema já tenha algumas vezes sido utilizado como enredo dos desfiles ele é materializado agora em alegorias, apontando para a responsabilidade social/ambiental das escolas de samba. 
Essa atitude não é a primeira, haja vista que em 2011 a própria Mocidade Independente de Padre Miguel já havia utilizado biodiesel como combustível de suas alegorias. No mesmo ano a Acadêmicos do Grande Rio pensou em formas de diminuir os resíduos gerados por suas fantasias fabricando-as a partir de materiais recicláveis:

\begin{abstract}
Algumas escolas de samba não fizeram bonito apenas na avenida. A Mocidade Independente de Padre Miguel, por exemplo, inovou em 2011 e utilizou biocombustível em todos os seus carros alegóricos. Foi a primeira vez na história do Carnaval carioca que o biodiesel foi utilizado como combustível para as alegorias.
\end{abstract}

Segundo matéria do blog Eco Verde, antes do carnaval, em 80 minutos de desfile seriam gastos, aproximadamente, 800 litros do combustível. "Pegaremos carona no enredo da Mocidade para o Carnaval ('Parábola dos Divinos Semeadores'), que destaca a importância da natureza. Estamos recolhendo também óleo residual de integrantes da escola para a confecção desse biodiesel", destacou Agostinho Filho, diretor da Escola de Samba de Padre Miguel, em entrevista ao blog.

Outro destaque da Sapucaí foi a Acadêmicos do Grande Rio. Pensando em diminuir a quantidade de resíduos gerados no Carnaval, a escola enviou seus convites para o camarote por e-mail, fez uso de papel reciclado nas dependências da festa e utilizou madeira recomendada pelo Instituto Brasileiro do Meio Ambiente (Ibama) nas estruturas das varandas. Além disso, a Escola Mirim Pimpolhos da Grande Rio, abriu o carnaval no Sambódromo carioca em um desfile com enredo sobre o meio ambiente e fantasias feitas a partir de materiais recicláveis (AGENDA 21, 2011).

A diferença entre as ações diz respeito ao fato de termos agora uma aposta nos grandes trunfos das escolas de samba - suas alegorias - que ganham destaque nas mídias em virtude do seu tamanho, tecnologia e materiais utilizados em sua confecção.

Nesse sentido percebemos a possibilidade que um fato como esse - a alegoria sustentável - seja um foco sobre a alegoria e por consequência sobre o conceito de sustentabilidade e seus nuances. Cabe aqui pensarmos no conceito de sustentabilidade, suas implicações, quais as relações que são articuladas quando acionamos o discurso da sustentabilidade? 
As duas últimas décadas testemunharam a emergência do discurso da sustentabilidade como a expressão dominante no debate que envolve as questões de meio ambiente e de desenvolvimento social em sentido amplo. Em pouco tempo, sustentabilidade tornou-se palavra mágica, pronunciada indistintamente por diferentes sujeitos, nos mais diversos contextos sociais e assumindo múltiplos sentidos (LIMA, 2003, p. 99).

Assim, podemos pensar, conforme ressalta Lima (2003), no discurso que nesta época é entendido como verdadeiro, o discurso da ciência que é rearticulado cada vez que buscamos movimentar conceitos como o de sustentabilidade, tendo como efeito uma reatualização dos significados da ciência sua potência enquanto verdade e uma preocupação com o ambiente, uma vez que este fato encontra-se na ordem do discurso.

Constata-se então que por vezes são pequenas ações ou ainda atitudes efêmeras - como as que narramos neste trabalho - que são movimentadas para que se dê conta da necessidade que se cria pelos discursos que são postos em circulação, mesmo que em um outro momento se perceba que isso tem pouco ou nenhum significado para as instituições.

\section{Algumas considerações}

Neste trabalho buscamos primeiramente dar conta dos locais de aprendizagem (formais, não formais, informais...) para dizer de nosso entendimento sobre outros espaços nos quais também se pode aprender sobre as Ciências por meio dos desfiles das escolas de samba. Não fizemos uma narrativa sobre o histórico, considerando que já existe um número significativo de trabalhos sobre essa temática e não gostaríamos de fazer desta pesquisa uma (re)narrativa do que já existe (muito do mesmo). Achamos mais prudente mostrar então nossos monumentos/documentos.

Não quantificamos, tampouco qualificamos o que se aprende, apenas afirmamos que se aprende sobre a ciência também nos desfiles das escolas de samba, conforme nossas escolhas do que aprender. 
Analisamos cada um dos documentos, e não encerramos ou dizemos que são os únicos encontrados, ao contrário, deixamos em aberto, apenas mostramos aqueles que nos parecem importantes para nosso foco, observar os ditos sobre a ciência, pensar na possibilidade de se aprender sobre a ciência com os desfiles das escolas de samba cariocas ou neste caso em seus entornos.

Uma possibilidade para ampliação deste estudo seria aplicá-lo em sala de aula e observar os seus efeitos no processo de ensino e aprendizagem, o que é de extrema validade, porém não foi nosso objetivo neste trabalho.

\section{Referências}

AGENDA 21. Folia sustentável. Comperj. Publicado em 4 mar. 2011. Disponível em: <http://agenda21 comperj.com.br/en/node/6970>. Acesso em: 28 jan. 2016.

ARRUDA, Sergio M. et al. O aprendizado científico no cotidiano. Ciência \& Educação, v. 19, n. 2, p. 481-498, 2013.

CRUZ, Adriana; MOURA, Athos. Escolas de samba "requebram" para superar crise e fazer carnaval de 2016. O dia. O dia na folia. 13 set. 2015. Disponível em: <http://odia. ig.com.br/diversao/carnaval/2015-09-13/escolas-de-samba-requebram-para-superar-crise-e-fazer-o-carnaval-de-2016.html>. Acesso em: 16 jan. 2016.

DA REDAÇÃO. Carnavália-Sambacon lança máquina para reciclar lixo do Carnaval. Portal Eventos. 28 jul. 2014. Disponível em: <http://www.revistaeventos.com.br/Feiras/ Carnavalia-Sambacon-lanca-maquina-para-reciclar-lixo-do-Carnaval>. Acesso em: 17 jan. 2016.

FALK, John H.; DIERKING, Lynn D. Learning from museums: visitor experiences and the making of meaning. Lanham/USA: Altamira Press, 2000.

FALK, John $\mathrm{H}$. The contribution of free-choice learning to public understanding of science. Inci, v. 27, n. 2, p. 62-65, feb. 2002.

FOUCAULT, Michel. Arqueologia do saber. Tradução Luiz Felipe Baeta Neves. 7. ed. Rio de Janeiro: Ed. Forense, 2007.

KINGVENDAS. Imagem: O que sua fantasia representa? Postado em 16 mar. 2012. Disponível em: <https://kingvendas.wordpress.com/page/51/>. Acesso em: 16 jan. 2016.

LETRAS. Samba-Enredo 1989. G.R.E.S. Unidos da Ponte. 1989. Disponível em: <https:// www.letras.mus.br/gres-unidos-da-ponte/samba-enredo-1989/>. Acesso em: 28 jan. 2016. 
LIMA, Gustavo da C. O discurso da sustentabilidade e suas implicações para a educação. Ambiente \& Sociedade, v. VI, n. 2, p. 99-119, jul./dez. 2003.

MARANDINO, Marta. A pesquisa educacional e a produção de saberes nos museus de ciência. História, Ciências, Saúde, Manguinhos, v. 12 (suplemento), p. 161-181, 2005.

MENDONÇA, Alba V. Mocidade Independente vai desfilar na Sapucaí com alegoria sustentável. G1 Rio. Carnaval 2016. 11 jan. 2016. Disponível em: <http://g1.globo.com/ rio-de-janeiro/carnaval/2016/noticia/2016/01/mocidade-independente-vai-desfilar-na-sapucai-com-alegoria-sustentavel.html>. Acesso em: 18 jan. 2016.

. Crise hídrica faz escolas do Rio reavaliarem uso de água em alegorias. G1 Rio. Carnaval 2015. 26 jan. 2015. Disponível em: <http://g1.globo.com/rio-de-janeiro/ carnaval/2015/noticia/2015/01/crise-hidrica-faz-escolas-do-rio-reavaliarem-uso-de-agua-em-alegorias.html>. Acesso em: 17 jan. 2016.

OVIGLI, Daniel F. B. et al. Espaço interativo do CBME: uma experiência em educação não formal. ENCONTRO NACIONAL DE PESQUISA EM EDUCAÇÃO E CIÊNCIAS, 6., 2007, Florianópolis. Anais... Florianópolis: Abrapec, 2007. Disponível em: <http:// www.nutes.ufrj.br/abrapec/vienpec/CR2/p924.pdf>. Acesso em: 17 jan. 2016.

PEDROSO, Elton. Manejo de produção de três espécies de aves alternativas: Catarina (Bolborhynchus lineola), Faisão Coleira (Phasianus colchicus torquatus) e Galinha Wyandotte (Gallus gallus domesticus). Relatório de Estágio. Curso de Agronomia. Universidade Federal de Santa Catarina. Florianópolis, 2014. Disponível em: <https:// repositorio.ufsc.br/handle/123456789/132241>. Acesso em: 17 jan. 2016.

PINTO, Leandro T.; FIGUEIREDO, Viviane A. O ensino de Ciências e os espaços não formais de ensino: um estudo sobre o ensino de Ciências no município de Duque de Caxias/RJ. SIMPÓSIO NACIONAL DE ENSINO DE CIÊNCIA E TECNOLOGIA, 2., 2010, Ponta Grossa. Anais... Ponta Grossa: UTFPR, 2010.

SULAIMAN, Samia N. Educação ambiental, sustentabilidade e ciência: o papel da mídia na difusão de conhecimentos científicos. Ciência \& Educação, v. 17, n. 3, p. 645-662, 2011.

VEIRA, Valéria; BIANCONI, Lúcia M.; DIAS, Monique. Espaços Não-Formais de Ensino e o Currículo de Ciências. Ciência \& Cultura, v. 57, n. 4, p. 21-23 out./dez. 2005.

YOUTUBE. Ciência dá Samba? (parte 2). Postado por CasadaCiencia. 2004. Disponível em: <https://www.youtube.com/watch?v=Xv0hnRkyQnE>. Acesso em: 28 jan. 2016.

Recebido em: 26/9/2016

Aceito em: 26/4/2017 